\title{
EFEITOS DA APLICAÇÃO FOLIAR DE CODAMIN E GRAIN-SET EM SOJA
}

\author{
Paulo R. C. Castro ${ }^{1}$
} Stella C. Cato ${ }^{1}$

\section{RESUMO}

Foram avaliados os efeitos das aplicações dos bioestimulantes Codamin-BR, Codamin-150 e Grain-Set, no crescimento e produtividade das plantas de soja (Glycine $\max$ cv. Paraná BRS-134) envasadas. Verificou-se que aplicações de Codamin-BR 250 ml.ha ${ }^{-1}$, Codamin-150 1,25 L.ha ${ }^{-1}$ e Grain-Set 0,5 L.ha $^{-1}, 40$ dias após a germinação (DAG), aumentou a altura das plantas de soja, tomada 10 dias depois (50 DAG). Codamin-BR, Codamin-150 e Grain-Set 0,5 e 0,25 L.ha-1 (aplicado aos 40 e 50 DAG) promoveram incremento na altura das plantas determinada 60 DAG. Aos 70 DAG somente os tratamentos com Codamin-150 e Grain-Set 0,5 L.ha ${ }^{-1}$ mantiveram aumentos na altura da soja. Os bioestimulantes não afetaram a massa seca das plantas (119 DAG), nem o número e a massa de vagens, a massa de grãos e a massa de 100 grãos, estabelecidos na colheita.

Palavras-chave: estimulantes vegetais, crescimento, produtividade, Glycine max.

\section{ABSTRACT \\ EFFECTS OF LEAF APPLICATION OF CODAMIN AND GRAIN-SET ON SOYBEAN.}

The action of biostimulant application on soybean (Glycine max cv. Paraná BRS-134) growth and production in vases was verified in this experiment. Applications of Codamin-BR 250 ml.ha ${ }^{-1}$, Codamin-150 1.25 L.ha ${ }^{-1}$ and Grain-Set 0.5 L.ha-1, 40 days after germination (DAG), increased soybean plant height checked 10 days later (50 DAG). Codamin-BR, Codamin-150 and Grain-Set 0.5 and 0.25 L.ha $^{-1}$, at 40 and 50 DAG, increased plant height established at 60 DAG. At 70 DAG just Codamin-150 and Grain-Set $0.5 \mathrm{~L}_{\text {h ha }} \mathrm{a}^{-1}$ maintained increases on soybean plant height. The biostimulants did not affect yield parameters determined at the harvest.

Key words: plant stimulants, growth, production, Glycine max.

\section{INTRODUÇÃO}

O cultivo da soja no Brasil tem incorporado técnicas de manejo e tecnologias das mais avançadas, fazendo com que a produtividade alcance níveis dos mais elevados. Os cultivares inseridos em sistemas de produção altamente tecnificados têm conduzido a excepcionais desempenhos quanto ao rendimento e economicidade.

Porém, condições edáficas e climáticas inadequadas, além de outros fatores, podem restringir o potencial de produção da soja. A utilização de biorreguladores e bioestimulantes pode suprir determinadas necessidades das plantas, no sentido de restituir a produtividade da cultura.

A grande utilização de aminoácidos e a exigência de micronutrientes pelas plantas levam a crer que a aplicação destes poderia promover desenvolvimento e

\footnotetext{
'Depto de Ciências Biológicas, Esalq-USP, Cx. Postal 09, 13418-900, Piracicaba, SP, Brasil.
} 
produtividade. Os produtos Codamin são corretivos de carências, com aminoácidos, muitas vezes associados a micronutrientes, podendo proporcionar rendimentos maiores e colheitas de melhor qualidade. Fornecem, além de aminoácidos, o ácido glutâmico necessário para a transaminase, que permite à planta sintetizar os aminoácidos que lhe são necessários naquele momento. A aplicação destes contribui para suavizar os efeitos da seca através de mecanismos não muito conhecidos, mas por meio dos quais se supõe que a prolina servirja para a sintese do material protéico necessário. Codamin-150 é constituído por um complexo de oligoelementos enriquecido com aminoácidos livres que penetram nas folhas até o citoplasma e na seiva, de forma que a planta pode aproveitar os micronutrientes ferto, manganês e zinco. A ação dos aminoácidos pode envolver um considerável aporte de energia para a planta, além de serem indispensáveis para a formação de proteínas. O produto tem sido recomendado para fases fenológicas críticas das plantas, como na brotação, florescimento, fixação e desenvolvimento dos frutos. Também pode aumentar a resistência das plantas ao déficit hídrico, geadas e outras condições estressantes. É constituido por 150 g. $\mathrm{L}^{-1}$ de aminoácidos livres, com $7,8 \%$ de nitrogênio total $(4,6 \%$ de $\mathrm{N}$ uréico e $3,2 \%$ de $\mathrm{N}$ protéico), $1,0 \%$ de ferro, $0,6 \%$ de manganês e $0,4 \%$ de zinco (Coda, 2000).

Grain-Set é um produto natural utilizado para melhorar a produtividade e a qualidade dos grãos. Além da formulação de ingredientes naturais, o produto contém um quelato orgânico de manganês, ajudando os cereais a atingir seu máximo potencial de produção. Recomenda-se somente uma aplicação de $500 \mathrm{ml}^{-h^{-1}}$, sendo que também possui ação surfactante. Culturas de cereais tratadas com Grain-Set podem ter maior produção, aumento no peso de 1000 grãos, aumento no número de grãos por espiga, incrementos no tamanho dos grãos e aumento da lucratividade (Improcrop, 2001).

Apesar da aplicação foliar de nutrientes ter sido demonstrada eficiente em numerosos trabalhos, uma vez que tem incrementado o conteúdo foliar dos nutrientes pulverizados nas folhas de citros (Castro et al., 2003), trabalho realizado por Boaretto et al. (2002) mostrou que menos de $10 \%$ das quantidades de $\mathrm{Zn}$ e Mn depositadas na superficie foliar são absorvidas, sendo suficientes para elevar os teores de micronutrientes das folhas que recebem a adubação foliar. Menos de $1 \%$ das quantidades de $\mathrm{Zn}$ e Mo depositadas nas folhas são transportadas para as partes da laranjeira que crescem após a adubação foliar, sendo insuficientes para alterar significativamente os teores foliares destes micronutrientes nestas partes.

Esse trabalho tem por objetivo avaliar os efeitos das aplicações de Codamin e de Grain-Set na soja 'Paraná BRS-134'.

\section{MATERIAL E METÓDOS}

O experimento foi realizado no Horto Experimental do Departamento de Ciências Biológicas da ESALQ, USP, em Piracicaba, SP. Sementes de soja (Glycine max cV. Paraná BRS-134) foram semeadas em 40 vasos, no dia 28 de julho de 2003 , germinando em 4 de agosto de 2003. Efetuaram-se desbastes deixando-se duas plantas por vaso. As plantas, distribuidas num delineamento inteiramente casualizado, foram submetidas aos 5 tratamentos, com 8 repetições. Aos 40 DAG constituíram-se os tratamentos: Controle, Codamin-BR $250 \mathrm{ml} \cdot \mathrm{ha}^{-1}\left(1,0 \mathrm{ml} \cdot \mathrm{L}^{-1}\right)$, Codamin-150 1,25 L.ha ${ }^{-1}$ (2,5 ml.L $\left.\mathrm{L}^{-1}\right)$ Grain-Set $0,5 \mathrm{~L} \cdot \mathrm{ha}^{-1}\left(1,7 \mathrm{ml} . \mathrm{L}^{-1}\right)$ e Grain-Set $0,25{\mathrm{~L} . h a^{-1}}^{-1}\left(0,8 \mathrm{ml} . \mathrm{L}^{-1}\right)$, sendo que esse último tratamento foi repetido aos 50 DAG. Todos os tratamentos foram acompanhados do surfactante Extravon 0,05\%.

Foram realizadas mensuraçōes da altura aos 50,60 e 70 DAG. Aos 119 DAG (início do florescimento) foi coletada uma planta para a determinação da massa seca da 
parte aérea. Aos 231 DAG determinou-se o número de vagens, a massa seca das vagens, a massa de 100 grâos e a massa de grãos por planta. Os dados obtidos foram submetidos a análise de variância (Tabela 1) e ao teste de Tukey ao nível de $5 \%$ de probabilidade (Pimentel-Gomes, 2000).

\section{RESULTADOS E DISCUSSÃO}

Pela Tabela 2 verificamos que Codamin-BR, Codamin- 150 e Grain-Set 0,5 L.ha I, aplicados $40 \mathrm{DAG}$, incrementaram a altura de plantas de soja determinada aos 50 DAG. Essas pulverizações, mais uma nova aplicação de Grain-Set 0,25 L.ha $^{-1}$, aos 50 $\mathrm{DAG}$, promoveram aumento na altura das plantas de soja aos $60 \mathrm{DAG}$. Aos $70 \mathrm{DAG}$ somente aplicações de Codamin-150 e Grain-Set 0,5 L.ha ${ }^{-1}$ mantiveram o aumento em altura das plantas de soja 'Paraná' BRS-134'.

Diversos trabalhos têm demonstrado que os sais minerais aplicados em pulverização foliar penetram na planta com maior ou menor eficiência, aumentando o conteúdo foliar dos nutrientes aplicados (Boaretto, et al., 2002; Castro et al., 2003).

Outros trabalhos mostraram que os aminoácidos aplicados na planta podem atingir o simplasto e moverem-se através das plantas (Schliemann et al., 1999; Kursanov, 1961; Nelson \& Gorham, 1959; Taiz \& Zeiger, 2004).

Codamin e Grain-Set são produtos capazes de atuar no desenvolvimento e produtividade das plantas (Coda, 2000; Improcrop, 2001).

Tabela 1. Análise de variância.

\begin{tabular}{lccccc}
\hline \multicolumn{1}{c}{ Causas da variação } & G.L. & S.Q. & Q.M. & Valor de F & Prob. $>$ F \\
\hline Trat & 4 & 316,52 & 79,13 & 3,18 & 0,02 \\
Resíduo (Trat) & 28 & 696,59 & 24,89 & & \\
\hline Parcelas & 39 & 1171,08 & & & \\
Tempo & 2 & 12568,66 & 6294,33 & 3127,69 & 0,00001 \\
Trat x Tempo & 8 & 67,01 & 8,38 & 4,17 & 0,00061 \\
Residuo (Tempo) & 70 & 140,65 & 2,01 & & \\
\hline Total & 119 & 13947,39 & & & \\
\hline C.V.(Trat) $=7,90 \% ;$ C.V. (Tempo) $=3,89 \%$ & & &
\end{tabular}

Tabela 2. Comparação das médias das alturas das plantas de soja 'Paraná' BRS-134', em três épocas de determinação, submetidas a aplicação foliar de bioestimulantes, pelo Teste de Tukey $(5 \%)$.

\begin{tabular}{|c|c|c|c|}
\hline \multirow[b]{2}{*}{ Tratamentos } & \multicolumn{3}{|c|}{ Altura (cm) } \\
\hline & 50 DAG & $60 \mathrm{DAG}$ & $70 \mathrm{DAC}$ \\
\hline Controle & $22,30 \mathrm{~b}$ & $33,32 \mathrm{c}$ & $46,58 b$ \\
\hline Codamin-BR $60 \mathrm{~L}^{-\mathrm{ha}^{-1}}$ & 25,09 a & $36,34 \mathrm{~b}$ & $48,00 \quad b$ \\
\hline Codamin-150250 ml.hl-1 & 24,92 a & 37,20 ab & 52,49 a \\
\hline Grain-Set $0,5 \mathrm{~L}^{\mathrm{ha}^{-1}}$ & 25,65 a & 38,40 a & 50,52 a \\
\hline Grain-Set 0,25 L.ha ${ }^{-1}$ & $22,14 \quad b$ & $35,70 \quad b$ & $47,88 \mathrm{~b}$ \\
\hline F (Trat x Tempo) & \multicolumn{3}{|c|}{$4,17^{\star \star}$} \\
\hline C.V. $(\%)$ & \multicolumn{3}{|c|}{7,9} \\
\hline
\end{tabular}

De acordo com a Tabela 3, podemos considerar que a aplicação dos bioestimulantes não afetou a massa seca da parte aérea estabelecida aos 119 DAG (antese floral). 
$\mathrm{Na}$ colheita, realizada aos $231 \mathrm{DAG}$, observamos que os bioestimulantes não modificaram o número de vagens, a massa de vagens por planta, a massa de 100 grãos, nem a massa de grãos por planta (Tabela 3).

Castro el al. (2004) verificaram que Codamin-150 e Codamin-BR aumentaram a fitomassa aérea de feijoeiro. Codamin-BR aumentou o número de grãos na colheita do fejjão. Codamin-BR e Codamin-150 incrementaram o peso de grãos colhidos de feijão 'IAC-Carioca Tybatã',

Tabela 3. Comparação das médias de massa seca da parte aérea, número de vagens, massa de vagens, massa de 100 grăos e massa de grãos por planta de soja, colhida aos $231 \mathrm{DAG}$, submetida a aplicação foliar de bioestimulante, pelo teste de Tukey $(5 \%)$.

\begin{tabular}{|c|c|c|c|c|c|}
\hline Tratamentos & $\begin{array}{c}\text { Massa seca } \\
\text { aérea (g) }\end{array}$ & $\mathrm{N}^{\circ}$ vagens & $\begin{array}{c}\text { Massa } \\
\text { vagens (g) }\end{array}$ & $\begin{array}{c}\text { Massa } 100 \\
\text { grăos (g) }\end{array}$ & $\begin{array}{c}\text { Massa } \\
\text { grãos (g) }\end{array}$ \\
\hline Controle & 29,25 a & 179,12 a & 91,86 a & 12,71 a & 48,77 a \\
\hline Codamin-BR $250 \mathrm{ml}, \mathrm{ha}^{-1}$ & 34,57 a & 194,87 a & 97,34 a & 12,82 a & 52,97 a \\
\hline Codamin-150 1,25 L.ha' & 35,01 a & 206,50 a & 107,67 a & 14,14 a & 61,09 a \\
\hline Grain-Set 0,5 L.ha ${ }^{-1}$ & 33,97 a & 213,12 a & 111,65 a & 14,11 a & 63,54 a \\
\hline Grain-Set $0,25 \mathrm{~L} \mathrm{ha}^{-1}$ & 32,15 a & 213,37 a & 105,65 a & 11,95 a & 58,70 a \\
\hline F (Trat) & $0,761^{\mathrm{mx}}$ & $0,522^{\mathrm{nt}}$ & $0,613^{\operatorname{nin}}$ & $1,634^{n x}$ & $0,813^{\mathrm{nh}}$ \\
\hline C.V. $(\%)$ & 23,18 & 28,26 & 28,31 & 16,00 & 33,28 \\
\hline
\end{tabular}

\section{CONCLUSÕES}

1. Codamin-BR $1 \mathrm{ml} \cdot \mathrm{L}^{-1}$, Codamin- $1502,5 \mathrm{ml} . \mathrm{L}^{-1}$ e Grain-Set $1,7 \mathrm{ml} . \mathrm{L}^{-1}$, pulverizados em soja 'Paraná' BRS-134' 40 DAG, aumentaram a altura das plantas determinada 10 dias depois (50 DAG).

2. Codamin-BR, Codamin-150, Grain-Set $1,7 \mathrm{ml}^{-\mathrm{L}^{-1}}$ e duas aplicą̧ões de GrainSet $0,8 \mathrm{ml} \cdot \mathrm{L}^{-1}$, incrementaram a altura de plantas de soja aos $60 \mathrm{DAG}$.

3. A aplicação dos bioestimulantes não alterou a massa seca da parte aérea determinada na antese floral nem os parâmetros de produção estabelecidos na colheita.

\section{REFERÊNCIAS BIBLIOGRÁFICAS}

BOARETTO, A.E.; MURAOKA, T.; BOARETTO, R.M.; UETA, F.Z. 2002. Absorção de micronutrientes aplicados via foliar pelos citros. $24^{\mathrm{a}}$ Semana de Citricultura, Palestra, Cordeirópolis, $14 \mathrm{p}$.

CASTRO, P.R.C.; GONÇALVES, M.R.; CATO, S.C. 2004. Effects of leaf application of Codamin and Brassinolide on bean plants. $50^{\circ}$ Reunión Annual de la Sociedad Interamericana de Horticultura Tropical, Resúmenes, La Mercedes de Guácimo, p. 21.

CASTRO, P.R.C.; KLUGE, R.A.; MEDINA, C.L.; CORRENTE, J.E. 2003. Management of infected plants with citrus variegated chlorosis (CVC) with bioregulators. $49^{\circ}$ Reunión Annual de la Sociedad Interamericana de Horticultura Tropical, Resumos, Fortaleza, p.43.

CODA, 2000. Nutrição vegetal. Catálogo Geral. Compañia de Agroquímicos, S.A., $11 \mathrm{p}$.

IMPROCROP, 2001. Grain-Set: para lavouras de cereais. Catálogo. Alltech, 1p. 
KURSANOV, A L. 1961. The transport of organic substances in plants. Endeavour, 20:19-25.

NELSON, C.D.; GORHAM, P.R. 1959. Physiological control of the distribution of translocated amino acids and amides in young soybean plants. Can. J. Bot., 37:439-447.

PIMENTEL-GOMES, F. 2000. Curso de Estatística Experimental. 14ªd. Piracicaba, $480 p$.

SCHLIEMANN, W.; KOBAYASHI, N.; STRACK, D. 1999. The decisive step in betaxanthin biosynthesis is a spontaneous reaction. Plant Physiol., 119:12171232.

TAIZ, L.; ZEIGER, E. 2004. Fisiologia Vegetal. Trad. E.L. Santarém et al., Artmed, Porto Alegre, 719p. 